\title{
A performance measurement framework for the South African bulk export wine supply chain
}

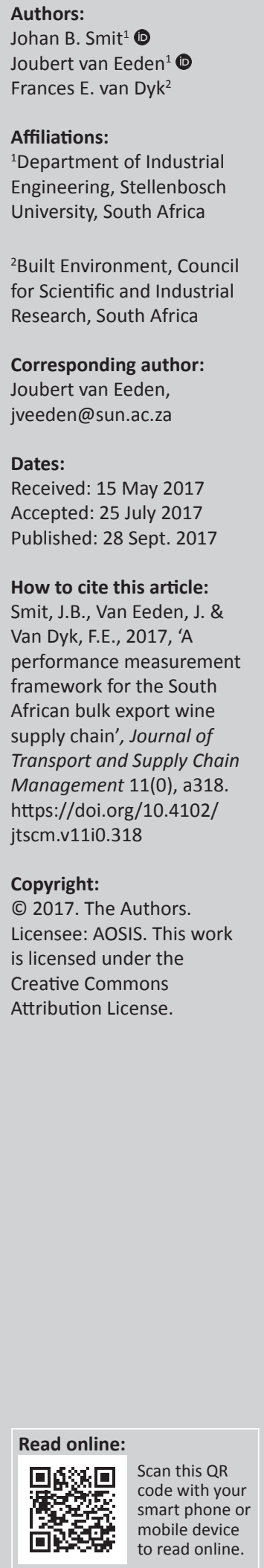

Authors:

Johan B. Smit

\section{Affiliations:}

Department of Industrial

Engineering, Stellenbosch

${ }^{2}$ Built Environment, Council for Scientific and Industrial

Corresponding author:

Joubert van Eeden,

How to cite this article: Smit, J.B., Van Eeden, J. \& Van Dyk, F.E., 2017, 'A framework for the South African bulk export wine supply chain', Journal of Transport and Supply Chain

Licensee: AOSIS. This work

is licensed under the

Creative Commons
Background: Many participants in the South African wine industry still exhibit low supply chain maturity in the management of their supply chains. This hampers export performance and ultimately client satisfaction. The development and tracking of appropriate metrics are key steps in improving supply chain performance.

Objectives: The purpose of this study was to develop a performance measurement framework for the South African wine industry, focussing on the bulk export segment.

Method: The framework was developed using an emergent multi-phased exploratory approach. The approach was implemented in two distinct phases, namely qualitative research followed by quantitative research in each of three iterations to develop and refine the framework. In each iteration, the qualitative research phase consisted of a literature survey, semi-structured and unstructured interviews and case studies, while the quantitative research phase consisted of the development, distribution, completion and analysis of the framework questionnaire, each iteration building on the framework outputs from the previous iteration.

Results: The research highlighted that the wine supply chain performance of bulk exports is hindered by the lack of a measurement culture, hampering the identification and prioritisation of interventions. The creation of a performance measurement framework in conjunction with industry, and informed by the Supply Chain Operations Reference framework, creates a platform for the industry to address these challenges.

Conclusion: The implementation of this framework will provide performance visibility for cellars in the wine industry. This would enable them to improve their logistics processes and increase their supply chain maturity, ultimately enabling benchmarking against competing supply chains both within South Africa and abroad, such as in Australia, Argentina and Chile.

\section{Introduction}

\section{Problem statement}

\section{Key focus}

In 2012, an exploratory supply chain study was conducted within South Africa's wine industry to identify supply chain performance gaps, opportunities and information available to inform decision-making. The research indicated that South Africa's wine industry lacks knowledge regarding supply chain concepts and its relevance to business performance and, as a result, has been underperforming as evidenced inter alia through high inventory levels and low profit margins (Van Eeden et al. 2013). Furthermore, cellars capture limited supply chain performance metrics. The measurements that are tracked vary significantly between cellars and are seldom used in their decision-making processes (PwC 2014). Supply chain benchmarking in this scenario is unattainable.

A set of key measurements need to be agreed upon and measured by all participants to enable comparison against their own historical performance, against other South African industry players and eventually against wine cellars from other countries. This will, in turn, inform decision-making that will support the wine industry in improving its current supply chain performance, leading to an increase in customer satisfaction and industry competitiveness.

In order to aid the development of a supply chain performance measurement (SCPM) framework for the South African wine industry, two key internationally recognised performance measurement frameworks are considered. These are the organisationally focussed Balanced Scorecard (BSC) developed by Kaplan and Norton in 1992, and the Supply Chain Operations Reference framework (SCOR) developed by the Supply Chain Council (SCC) in the 1990s and owned by the APICS 
Supply Chain Council since 2014. These frameworks aim to find a balance between short-term and long-term organisational excellence through the application of a balanced set of financial and non-financial performance measurements to all the areas of a business.

\section{Background}

The South African wine industry has a rich history dating back to 1659. It has experienced substantial growth since its origin, now comprising nearly 600 cellars, which contributed R36.1 billion to the South African gross domestic product (GDP) in 2013, with record harvests registered in 2012-2014 (Conningarth Economists 2015; SAWIS 2017). Because of this oversupply period, cellars entered into emerging international markets, that is, China, Russia and Nigeria, each with their own unique set of import regulations. As a result, the logistics activities became more complex, and supply chain visibility and maturity are becoming increasingly important.

An important output of the preliminary study (Van Eeden et al. 2013), which formed the basis of this research, was market segmentation. Four unique market segments were identified in South Africa's wine industry, namely bulk export, bulk local, packaged export and packaged local, to distinguish between the unique processes, products and markets relevant to these segments. This article reports on the subsequent study conducted on the South African bulk export wine supply chain, specifically the section of the supply chain from after the wine has been produced until delivery at the port of discharge (POD) (see entities highlighted in blue in Figure 1). The salient results of the preliminary study will also be reported as it provided important inputs to frame the segment-specific research.

\section{Objectives and scope}

The key objectives of this study were the following:

- to determine the level of supply chain information available in the bulk export chain

- to identify performance indicators for the bulk export wine supply chain that can be used as benchmark metrics to improve decision-making and ultimately supply chain performance

- to create an ideal framework for measuring performance indicators with the future aim of benchmarking.

\section{Contribution to field}

The development of a pragmatic performance measurement framework for the South African bulk export wine supply chain will advance industry supply chain maturity through promoting a supply chain orientation towards customer satisfaction and through providing metrics to support this.
The framework is relatable to the internationally established SCOR framework in order to ultimately facilitate benchmarking, yet based on local needs and data availability to allow for organisational adoption and actionable outcomes. This can serve as a practical approach to developing performance measures for other emerging economies or industries with lower levels of supply chain maturity.

In the next section, the literature review is summarised, following which the research methodology is described. 'Findings and results' describes the results of each iteration of the framework, culminating in the ideal framework. The practical implications of the research, as well as the research limitations, are also elucidated, followed by concluding remarks.

\section{Literature review}

\section{Supply chain performance measurement}

The supply chain's performance is affected by a diverse set of variables, such as supply chain management and planning decisions, as well as supply chain design decisions (Pero et al. 2010). According to Estampe et al. (2010), the performance of a supply chain can be measured in terms of both the customers' level of satisfaction and the cost incurred, where the ultimate aim is fully engaged customers who cocreate value in the supply chain in collaboration with other stakeholders in order to reduce the total cost of ownership of the chain. Camerinelli (2009) reviewed a survey that asked a large number of European companies to list the three most common metrics they use to measure the performance of their supply chains. These included delivery performance and customer service level, cost reduction and efficiency. Customer service excellence is the overriding supply chain function that can create demand and retain customer loyalty, and as such render a competitive advantage to the organisation (Christopher 2005). It is therefore important to define metrics with a view of adding value to the customer. In order to identify suitable measurements, quantitative and qualitative information should be gathered to increase supply chain understanding.

Gunasekaran, Patel and McGaughey (2004) divided an organisation's supply chain activities into four areas which can serve as a framework for SCPMs, namely plan, source, make and deliver, where each activity has a strategic, tactical and operational level. The strategic level includes high-level decision-making where long-term and medium-term goals are developed. The tactical level includes calculated decisions to ensure that the strategic level goals are met. Lastly, the operational level involves day-to-day decisions made by front-line or low-level managers. The assignment of supply chain activities to the different levels as appropriate also

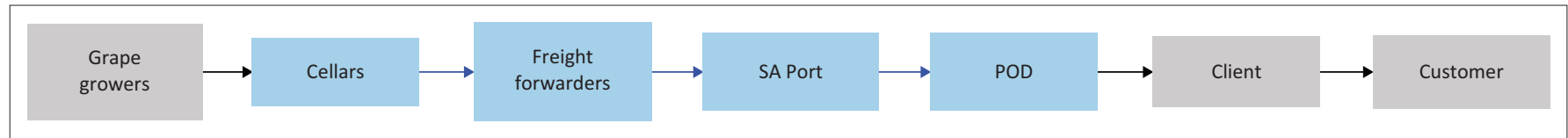

FIGURE 1: High-level representation of South Africa's export supply chain. 
designates the responsibilities for each measurement. This, in turn, highlights the information streams within the organisation and where it is lacking.

Neely (2002) identified key requirements of effective performance measurement frameworks:

- There are a limited number of measures.

- The non-financial processes-focussed metrics are seen as leading indicators.

- The measuring system is stable and creates an awareness regarding long-term goals.

Akyuz and Erkan (2010) confirmed that failing to align the measurements with the organisation's strategy and measuring a large number of metrics are the key pitfalls of SCPM. In addition, performance metrics should adhere to the following principles:

- Base the performance measurements on the industry's strategies and objectives.

- Balance non-financial and financial measures according to the industry's strategies.

- Be comparable to other performance measures used by similar industries.

- Define and standardise data collection and calculation methods.

- Use performance measurement results for strategic, tactical and operational decision-making.

- Prioritise metrics.

Beamon (1999) defined the relationship between measurements by dividing performance measurements into three types, namely resource measures, flexibility measures and output measures. Resource measures consist of inventory levels, equipment utilisation and energy usage, among others. Flexibility measures accommodate the volume fluctuations in a supply chain while output measures consist of customer responsiveness, quality and quantity of products. Each makes a vital contribution to performance measurement because one aspect of the supply chain affects the others. For example, if focussing only on a single measure of the supply chain's performance such as cost reduction, it could result in poor customer response time, poor performance or lack of flexibility. Therefore, measuring a single performance measure ignores the interactions between characteristics in a supply chain and is therefore generally inadequate.

Lambert and Pohlen (2008) extended this view of supply chain interactions to managing customer relationship and supplier relationship interfaces and processes at each link in the supply chain, in order to align objectives and improve profitability across the entire supply chain. This requires buyin from and collaboration between the multiple firms within the chain, and often entails joint investments and therefore presupposes a high level of supply chain maturity, defined as 'extended supply chain maturity' by Lockamy and McCormack (2004). This is in line with the three degrees of supply chain complexity defined by Mentzer et al. (2001):
- Direct supply chain: consists of a firm, its immediate supplier and immediate customer involved in the upstream or downstream flows of products, services, finances or information.

- Extended supply chain: includes suppliers of the immediate supplier and customers of the immediate customer, all involved in the upstream or downstream flows of products, services, finances or information.

- Ultimate supply chain: includes all the organisations involved in all the upstream or downstream flows of products, services, finances or information from the ultimate supplier to the ultimate customer.

To conclude, the major requirements to take into consideration when developing SCPM are an awareness of the firm's position within the industry and the supply chain, prioritising key metrics in line with the organisational strategy and, where possible, the broader aforementioned awareness, measuring financial and non-financial metrics and understanding and managing the trade-off between metrics. The goal of individual firms should be to work towards increased collaboration with other supply chain participants as maturity increases in order to optimise the performance of the total chain.

For the purposes of this project, given the low levels of supply chain maturity within the South African wine industry, the cellars' direct downstream supply chain, that is, the interface with the immediate customer as defined by Incoterms, is measured. As the measurement culture matures, this should be expanded to include other players in the chain (as shown in Figure 1), until the ultimate supply chain (as defined above) can be measured and optimised.

\section{Performance measurement frameworks}

The only wine-specific SCPM located during the literature survey was developed by Garcia et al. (2011) for the wine industry of Argentina. The authors segmented the Argentinian wine industry according to price and quality. The division of segments was not transferrable to the South African wine industry. Two established performance measurement frameworks were therefore reviewed in order to provide context for this study. These are the BSC and SCOR.

Balanced scorecard: In 1992, the BSC was developed by Kaplan and Norton as a performance measurement framework that combined financial and non-financial metrics to give managers a 'balanced' view of organisational performance (Balanced Scorecard Institute 2017). Kaplan and Norton (2005) viewed the use of financial measurements alone as inadequate because it could give misleading signals that interfere with innovation and continuous improvement. The financial measurement will indicate the after-effect of innovation and continuous improvement, but will not necessarily initiate them. In order to fully analyse organisational performance, it is necessary to measure both financial and non-financial metrics. Consequently, Kaplan and Norton (2005) developed the 
BSC. The BSC views the organisation from four perspectives, namely the Learning and Growth Perspective, Business Process Perspective, Customer Perspective and Financial Perspective. These perspectives minimise the information overload, giving managers four areas to focus on, from which to measure their performance. It delivers results in a single report allowing managers to see whether one area has improved at the expense of another (Kaplan \& Norton 2005).

The BSC is a well-researched performance management framework and has earned its credibility in the industry. Therefore, the following aspects were used as guidelines to develop a framework for the South African bulk wine supply chain:

- to create a dashboard of key metrics through which the organisation can be viewed as a balanced entity in order to, inter alia, gain an understanding of the trade-offs between financial and non-financial metrics

- to ultimately, incorporate the perspectives of all stakeholders into organisational decision-making in order to facilitate the long-term sustainability of the organisation.

Supply Chain Operations Reference performance measurement framework: SCOR is a framework used to identify, measure, evaluate, describe and prioritise supply chain configurations within the organisation (APICS SCC 2017). SCOR proposes five performance attributes, namely agility, reliability, responsiveness, cost and assets. These attributes are used to measure a supply chain on specific performance areas. Each attribute is divided into a hierarchy of three levels, where the third level is diagnostic measures. In addition to the SCOR framework, the SCC provides a roadmap to implementing the framework, which consists of six phases (refer Figure 2).

\begin{tabular}{|c|c|c|c|}
\hline Phase & Name & Deliverable & Resolve \\
\hline 0 & Organise & Organizational support & Who is the sponsor? \\
\hline 1 & Discover & $\begin{array}{l}\text { Supply chain definition } \\
\text { Supply chain priorities } \\
\text { Project charter }\end{array}$ & $\begin{array}{l}\text { What will the program } \\
\text { cover? }\end{array}$ \\
\hline 2 & Analyse & $\begin{array}{l}\text { Scorecard } \\
\text { Benchmark } \\
\text { Competitive requirements }\end{array}$ & $\begin{array}{l}\text { What are the strategic } \\
\text { requirements of your } \\
\text { supply chain? }\end{array}$ \\
\hline 3 & Material & $\begin{array}{l}\text { Geo map } \\
\text { Tread diagram } \\
\text { Disconnect analysis }\end{array}$ & $\begin{array}{l}\text { Initial analysis - where } \\
\text { are the problems? }\end{array}$ \\
\hline 4 & Work & $\begin{array}{l}\text { Transaction } \\
\text { Level 3, Level } 4 \text { processes } \\
\text { Best practice analysis }\end{array}$ & $\begin{array}{l}\text { Final analysis - where } \\
\text { are the solutions? }\end{array}$ \\
\hline 5 & Implement & $\begin{array}{l}\text { Opportunity analysis } \\
\text { Project definition } \\
\text { Deployment organisation }\end{array}$ & How to deploy? \\
\hline
\end{tabular}

Source: APICS SCC, 2017, The most recognized supply chain framework, viewed 28 April 2017, from http://www.apics.org/apics-for-business/products-and-services/apics-scc frameworks/scor

FIGURE 2: Supply Chain Operations Reference framework implementation roadmap.
Phases 0 and 1 of SCOR revolve around a change management process to ensure organisational buy-in of the process, as well as a common understanding of the supply chain priorities. In Phase 2, a benchmark study can be implemented to reveal gaps in the organisation's logistics processes. Metrics that have the greatest effect on logistics performance should be selected for a benchmarking study. These will be used to identify gaps between the organisation and benchmarking partners for the selected metrics. In Phases 3 through 5, the supply chains that were prioritised in Phase 1 are now analysed and initial problems are identified, solutions proposed and improvement projects implemented.

SCOR was chosen to be best suited as the primary contributor for this study because it already incorporates supply chain activities between suppliers and provides measurements for them.

The guidelines from the BSC were used in conjunction with SCOR's existing framework, to enhance the effectiveness of the ideal framework developed for the South African wine industry.

In the next section, the research method and design are discussed.

\section{Research method and design Material and setting}

The subject studied in this research was wine cellars and their supply chain performance related to the export of bulk wine. More than $95 \%$ of South African wine cellars are located in the Western Cape of South Africa.

\section{Design}

The framework was developed using an emergent multiphased exploratory approach. The approach was implemented in two distinct phases, namely qualitative research followed by quantitative research in each of three iterations to develop and refine the framework. In each iteration the qualitative research phase consisted of a literature survey, semi-structured and unstructured interviews and case studies, while the quantitative research phase consisted of the development, distribution, completion and analysis of the framework questionnaire, each iteration building on the framework outputs from the previous iteration (in line with Creswell \& Plano Clark 2006).

Twenty-four cellars, representing 33\% of the bulk export segment volume, and $23.4 \%$ of all wine produced in South Africa, participated in the complete study. The percentage representation was deemed sufficient for the purpose of this study because of the fragmented nature of the wine industry. These cellars represent most of the wine regions in South Africa. Four freight forwarders, who collectively facilitate over $75 \%$ of the South African wine exports, were included in the second iteration of the study (to expand the information sources). 


\section{Procedure and analysis}

The extensive research project over a time of 2 years was divided into the following three iterations:

- Iteration 1: Investigation of the South African wine industry and designing a preliminary framework.

- Iteration 2: Revising the preliminary framework with specific reference to the South African bulk export wine supply chain.

- Iteration 3: Developing an ideal framework for the South African bulk export wine supply chain.

Iterations 2 and 3 were completed for all four market segments identified during Iteration 1 . This article reports on the results for the bulk export segment. The results for the other segments will be published in due course. (Refer to Jooste, Van Eeden \& Van Dyk [2015] for packaged local outputs. Packaged export publication is in process.)

During each iteration, literature was reviewed, semistructured and unstructured interviews were conducted and case studies were developed, in order to obtain the most relevant information regarding the development of the framework. The interviews were conducted with participating cellars, freight forwarders and the Department of Agriculture, Forestry and Fisheries. In addition, PwC, an auditing firm that annually compiles a financially focussed wine industry insights survey, was approached to provide inputs regarding the financial aspects of the cellars. The Cape Town port was not interviewed, as total wine exports for 2014 accounted for only 3.25\% of the Cape Town port's total exports (Transnet 2014; WOSA 2015). The freight forwarders however had access to the required information regarding the Cape Town port processes and the POD.

In Iteration 1, the research team became acquainted with the industry through scheduled workshops with the initial 16 participating cellars. The workshops included the cellars' financial directors, marketing managers and chief executive officers. The workshops' primary focus was to aid strategic prioritisation by identifying which two of the four segments within the South African wine industry the cellar focusses on, or wishes to focus on, and to identify for which SCOR attributes (refer section 'Supply Chain Operations Reference performance measurement framework') the cellars wanted to achieve superior advantage or parity performance for each selected segment. According to the SCOR metrics, only one attribute may be selected at superior level, but up to two attributes can be selected at advantage level (APICS SCC 2012). These levels are defined as follows:

- Superior: Top $10 \%$ of industry.

- Advantage: Top 30\% of industry.

- Parity: Top $50 \%$ of industry.

These workshops and semi-structured interviews steered the cellar management teams' thinking in the direction of supply chain concepts. In addition, these interactions gave preliminary indications of the quality of information and data available in the industry.

After the workshops and semi-structured interviews were completed, sufficient information had been gathered to develop a preliminary performance measurement framework. This framework included metrics from each of the five attributes of SCOR, seeing that the attributes consisted of financial and non-financial metrics and are trade-offs of one another. The objective of the preliminary framework was to determine the availability of the quantitative data, as discussed during the workshops.

The metrics were designed on Microsoft Excel with a clear description of the metrics and how to calculate each one. The Excel file was sent via email to all participating cellars. The feedback was received via email, after which the analysis of the quantitative data commenced. The research team analysed each metric that had been measured by the cellars. Conclusions were drawn for each metric, and workshops were arranged to share the feedback to the cellars. The knowledge obtained from analysing the quantitative data, together with the feedback received from the workshops, formed the point of departure for Iteration 2.

In Iteration 2, the first objective was to investigate the feedback received from Iteration 1's measurements, workshops and the problems that surfaced during this iteration. The next objective was to refine the preliminary framework for application in the bulk export wine supply chain. In order to expand the representative scope of the segment, eight more cellars and additional industry service providers were added. The metrics were selected on the basis of the level of data that was available in the industry and the feedback received during Iteration 1 . There are many limitations regarding quantitative data availability in the South African wine industry and therefore not all SCOR attributes were measured for Iteration 2.

In order to improve survey security and accuracy, funds were made available to design the Iteration 2 survey on SurveyMonkey (2015). The data requested for Iteration 2 could not be collected at the cellars alone, seeing that they do not capture all the requested data on their systems. Data were also collected from other sources, such as freight forwarders. By collecting the data directly from their industry partners, this ensured easier access and increased the cellars' willingness to participate.

During Iteration 3, an ideal framework was developed for the bulk export segment using the results from the Iteration 1 and Iteration 2 surveys, the literature review, interviews and workshops. Moreover, this framework was not developed based on the limitations of information and data currently available in the industry. Rather, it proposes the metrics that should be measured if all information and data were available. The quantitative phase of this final iteration falls outside the scope of this project and is to be completed in future work. 


\section{Findings and results} Iteration 1 results

Results from the workshops and interviews showed that the primary strategy of a cellar focussing on bulk export is to have a reliable bulk export supply chain (Van Eeden et al. 2014). In line with the criteria to align performance metrics with the organisational strategy, the key metrics for each SCOR attribute were identified to support the segment's primary strategy, and an initial measurement framework was developed.

The attempt to populate this framework established that the level of supply chain information available in the bulk export chain is very limited, concomitant with low levels of supply chain maturity. Table 1 highlights the data challenges within the sampled cellars and provided a starting point to develop a refined performance measurement framework during Iteration 2. The three attributes with partial data availability were selected for refinement during Iteration 2. Transportation cost was not selected for Iteration 2 because the cost for transport is directly proportional to the location of the cellars. This difference was expected and would not facilitate decision-making in this regard. Data for the remaining attributes, namely agility and storage cost, were not available. It was therefore not included in Iteration 2 but underwent further improvement during the development of the ideal framework. Although much time was spent in all the iterations on attempting to find a meaningful method of including a metric for inventory carrying cost, it was eventually excluded because of reasons to be explained later.

\section{Iteration 2 results}

The three attributes with partial data availability in Iteration 1 , namely reliability, responsiveness and assets, were refined during Iteration 2. The metrics for these attributes were disaggregated in more detail through the processes described in the methodology (see Table 2), which increased the understanding of the issues pertaining to the metric.

The metrics for the reliability attribute was informed by the so-called Perfect Order Index, which is defined as an order that is shipped complete, delivered on time and error-free (damage-free and accompanied by the correct documentation and invoicing) (Vitasek \& Symmes 2007). The metrics for the responsiveness attribute was chosen based on the key order fulfilment cycle time metrics of importance to bulk exports, relating to the cycle time from order to arrival at the port, from the port to loading on the vessel and from vessel loading to POD. For the asset management attribute, inventory management was identified during the interviews as a key differentiating factor within the wine industry, as well as one of the areas with the most opportunities for improvement. Therefore, the level 2 metric 'inventory days of supply' (IDOS) was identified as the most appropriate metric. This was calculated for bulk exports in total, and then separately for spot bulk and contracted bulk. Spot bulk is an industry term wine used for bulk wine that is ordered during the year, meaning no long-term contract was in place.

As can be seen from Table 2, there were still significant challenges with data availability and quality, despite these metrics being identified as important by the industry. The design of the ideal framework was based on the learnings from Iterations 1 and 2, guided by the SCOR metrics, while ensuring both applicability and practicality. The framework was improved by obtaining inputs from both cellars and freight forwarders through the Iteration 2 questionnaire. The extent of input leading to the development of the ideal framework (interviews, workshops, literature reviews and responses on two questionnaires) improves the robustness of the framework, as well as the ownership by industry.

TABLE 1: Summary of the data quality for Iteration 1.

\begin{tabular}{|c|c|c|c|c|c|c|c|}
\hline SCOR attribute & Metric & Data availability & Completeness & Consistency & Accuracy & Transparency & Traceability \\
\hline Reliability & Perfect order fulfilment & Partial & No & Yes & No & No & Yes \\
\hline Responsiveness & Order fulfilment cycle time & Partial & No & Yes & No & No & No \\
\hline Agility & Upside supply chain flexibility & No & - & - & - & - & - \\
\hline \multirow[t]{2}{*}{ Cost } & Storage cost & No & - & - & - & - & - \\
\hline & Transportation cost & Yes & Yes & Yes & Yes & No & Yes \\
\hline Asset & Inventory days of supply & Partial & Partial & No & Partial & No & Yes \\
\hline
\end{tabular}

SCOR, Supply Chain Operations Reference framework.

TABLE 2: Summary of the data quality for Iteration 2.

\begin{tabular}{|c|c|c|c|c|c|c|c|}
\hline Attribute & Metric & Data availability & Completeness & Consistency & Accuracy & Transparency & Traceability \\
\hline \multirow[t]{4}{*}{ Reliability } & Percentage of orders delivered in full & No & - & - & - & - & - \\
\hline & Delivery performance to customer commit date & Yes & Partial & Yes & Partial & Partial & Yes \\
\hline & Documentation accuracy & No & - & - & - & - & - \\
\hline & Perfect condition & No & - & - & - & - & - \\
\hline \multirow[t]{4}{*}{ Responsiveness } & Order date & No & - & - & - & - & - \\
\hline & Time arrived at port & No & - & - & - & - & - \\
\hline & Time loaded on ship & Yes & Yes & Yes & Partial & Partial & Yes \\
\hline & Time discharged at POD & Yes & Yes & Yes & Partial & Partial & Yes \\
\hline \multirow[t]{3}{*}{ Asset } & Total bulk export IDOS & Yes & Partial & Partial & Partial & Partial & Yes \\
\hline & Spot bulk export IDOS & Yes & Partial & No & Partial & Partial & Yes \\
\hline & Contracted bulk export IDOS & Yes & Partial & No & Partial & Partial & Yes \\
\hline
\end{tabular}

IDOS, inventory days of supply. 


\section{Iteration 3: Ideal framework}

The ideal framework, shown in Table 3, includes four of the five SCOR attributes. The selected metrics for each of the four SCOR attributes are discussed briefly in separate sections below. In short, all the Iteration 2 metrics were carried over to the Iteration 3 framework, except for the reliability metric 'percentage of orders delivered in full'. This is because of the unique bulk wine scenario where a customer would order an estimated quantity required, but the ordered amount would be adjusted to the final volume loaded at shipping. This final quantity could vary, within agreed tolerances, because of the filtration and stabilisation process required. This is standard practice given the nature of wine as a product. In addition, three supplementary metrics were added to the asset attribute, as described in section 'Asset management'. The cost attribute from Iteration 1 was included in the ideal framework, and the key cost metrics defined. Because of continued challenges with defining and measuring the SCOR agility attribute, metrics for this attribute are not included in the ideal framework yet. A significant amount of work is still required to refine and finalise agility metric(s) for the wine industry. This will be reported on in subsequent publications.

The attributes and metrics of the ideal framework are now described in turn.

\section{Reliability}

The cellars have a responsibility to their customers to deliver the correct quantity and quality of wine on time and with correct documentation; therefore, the delivery performance to customer commit date, perfect condition and documentation accuracy were selected as metrics to measure reliability. Because the majority of wine is shipped according to free-onboard, the cellar's responsibility stops after the wine is loaded onto the ship. Thereafter, the customer's (the importer's) responsibility starts. However, the customer can only verify the quality and quantity when the wine is delivered at the customer's warehouse, which implies that the cellar is responsible for the correct quality and quantity of wine until then. Therefore, the customer experiences South Africa's cellar's time and documentation reliability until the wine is loaded onto the ship, and the quantity and quality reliability throughout the shipping process (see Figure 3).

\section{Responsiveness}

The activities prior to shipping are mostly within the cellar's control. Cellars have to prepare the wine for shipment, complete or outsource the necessary documentation and give notice to deliver the wine at the port. Therefore, responsiveness is mostly the cellar's responsibility.

TABLE 3: Metric definitions: Ideal framework - bulk export (metric formulas in Table 1-A1).

\begin{tabular}{|c|c|c|c|}
\hline Attribute & Metric & Formulas (Appendix A) & Definition \\
\hline \multirow[t]{3}{*}{ Reliability } & $\begin{array}{l}\text { Delivery performance to } \\
\text { customer commit date }\end{array}$ & 1 & Percentage of orders for which all of the items are received by customer on time. \\
\hline & Documentation accuracy & 2 & Percentage of orders for which all of the items are received by customer with correct documentation. \\
\hline & Perfect condition & 3 & $\begin{array}{l}\text { Percentage of orders delivered in undamaged state that meet specification, have the correct } \\
\text { configuration, are faultlessly delivered and accepted by the customer. }\end{array}$ \\
\hline Responsiveness & $\begin{array}{l}\text { Order fulfilment cycle } \\
\text { time }\end{array}$ & 4 & $\begin{array}{l}\text { The average actual cycle time consistently achieved to fulfil customer orders. For each individual } \\
\text { order, this cycle time starts from the order receipt and ends with customer agreed date at the agreed } \\
\text { point of acceptance, as determined by the Incoterms. }\end{array}$ \\
\hline \multirow[t]{5}{*}{ Cost } & Transportation cost & 5 & The cost associated with the physical transportation of goods between supply and demand nodes. \\
\hline & Purchased material cost & 6 & The total cost of chemicals, cleaning and filtration. \\
\hline & Production labour cost & 7 & The total cost associated with the personnel performing the activities of Make. \\
\hline & Return cost & 8 & $\begin{array}{l}\text { The total cost of disposition of materials returned because of planning errors, supplier quality, } \\
\text { production, order management, quality rejections and delivery errors. }\end{array}$ \\
\hline & Storage cost & 9 & The cost associated with tanks designed to support the fulfilment of customer orders. \\
\hline \multirow[t]{6}{*}{ Asset } & IDOS - total bulk export & 10 & The volume of bulk export inventory expressed in days of sales. \\
\hline & $\begin{array}{l}\text { IDOS - contracted bulk } \\
\text { export }\end{array}$ & 11 & $\begin{array}{l}\text { The volume of contracted bulk export inventory expressed in days of sales. (Contracted bulk is wine } \\
\text { that is ordered in advanced before the end of harvest for that year.) }\end{array}$ \\
\hline & IDOS - spot bulk export & 12 & The volume of spot bulk export inventory expressed in days of sales. \\
\hline & $\begin{array}{l}\text { Days payable outstanding } \\
\text { (creditor days) }\end{array}$ & 13 & $\begin{array}{l}\text { The length of time from purchasing materials dry goods (bottles, labels, corks, capsules and boxes) } \\
\text { until cash payments must be made expressed in days. }\end{array}$ \\
\hline & $\begin{array}{l}\text { Days sales outstanding } \\
\text { (debtor days) }\end{array}$ & 14 & $\begin{array}{l}\text { The length of time from when a sale is made until the cash is received from customers. The number of } \\
\text { sales expressed in days. }\end{array}$ \\
\hline & Cash-to-cash & 15 & $\begin{array}{l}\text { The time it takes for an investment made to flow back into a company after it has been spent for raw } \\
\text { materials (focussing on bulk export segment). }\end{array}$ \\
\hline
\end{tabular}

IDOS, inventory days of supply.

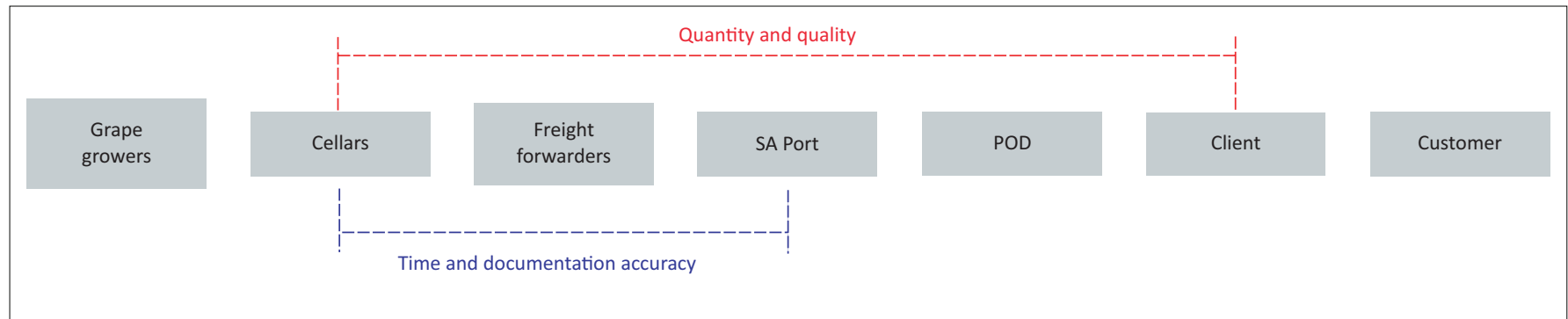

FIGURE 3: Cellars' responsibility regarding reliability. 
For the ideal framework, the first section of responsiveness was measured from when the order was placed, to its arrival at the Cape Town port. The second section was measured from when the ship departed from Cape Town port to the POD. The second measurement can be used in future when the South African bulk export framework is comparable to other southern hemisphere wine countries. The time between delivery at port and departure is outside the cellar's control, but related to port efficiencies, and not measured per se.

\section{Cost}

Of all the metrics, identifying the appropriate cost metrics and obtaining the data from cellars proved to be the most challenging. Numerous cost metrics were selected to form part of the cost attribute, however, this attribute is not restricted to the identified metrics. These metrics are listed below:

- transportation cost

- purchased material cost (chemical, cleaning and filtration costs)

- labour (direct and indirect) cost

- return cost

- storage cost.

Most firms would try to contain cost, but it is a trade-off for the other attributes. These cost metrics should thus be tracked to monitor the cost impact of improvement decisions that would influence other attributes positively, without overspending on cost aspects.

Cellars can select other cost metrics that would support a relationship between the cost attribute and other attributes in order to monitor the effect that other attributes have on cost. The reliability and responsiveness of wine that is exported are largely affected by the road transport, the flexi-tank provider, documentation, freight forwarders and shipping lines. As such, measuring all transportation costs to the point where the cellar's responsibility ends would represent the reliability and responsiveness attributes' effects on cost the best. This is the cellar's choice, but for initial implementation purposes, the transportation cost should be seen as one metric without sub-divisions.

According to a survey conducted by PwC (2014), labour (direct and indirect) is the highest cost, whereas purchased material cost (chemical, cleaning and filtration costs) is the second highest cost. Because these are major expenses for cellars participating in the bulk export segment, it should be monitored and measured in R/litre.

Inventory carrying cost is an important metric that the researchers felt should have been included. Inventory carrying cost is a function of the volume, the value and the capital cost rate. The practices in the wine industry for inventory valuation were found to be very subjective, aiming at non-supply chain focussed objectives such as tax postponement and managing wine harvest year pooling systems, among others. Upwards value adjustments often occur at the time of selling bulk wine and would thus make product value a very subjective component to use in a comparative benchmarking framework. Another aspect was the different wine ageing requirements forcing higher inventory volumes for some cellars. Different cellar sizes would make the volume alone irrelevant, even if a standard capital rate was considered. Although not ideal, the inventory volume relative to sales volume included in the IDOS metric (Assets) was thus considered sufficient to provide an indication of hiding poor supply chain planning with excessive inventory.

The final cost metric identified is storage cost. Because bulk wine is stored in tanks, the cost for storing wine will only include direct costs associated with the tanks that are used to store the wine. This includes the cost of leasing, rent, depreciation, acquisition, maintenance, labour cost and expenses of internal or external maintenance.

Operations that should be included in the cost metrics or the detail of it is subject to interpretation. Seeing that it is an internal benchmark earmarked for future competitive benchmarking, it is imperative that the metrics are measured consistently throughout the industry, ultimately leading to better decision-making.

\section{Asset management}

The metrics (shown in Table 3) selected to form part of the ideal framework for this attribute are IDOS for bulk export and cash-to-cash cycle time. As already mentioned, IDOS should be calculated in a segmented manner. For the cash-tocash metric, the bulk export IDOS should be used. After the IDOS has been calculated, there remain two other variables to calculate, namely days sales outstanding (or debtor days) and days payable outstanding (or creditor days). Cellars are highly dependable on cash availability (PwC 2014). Wine that is sold in bulk format provides a shorter cash-to-cash cycle as wine that is being packaged. This is one reason why some cellars would sell the majority of their wine in bulk format, if the opportunity presents itself. It is difficult for cellars to make business decisions without knowing how long it takes for raw material to be converted into cash. Therefore, this measurement creates internal visibility on which business decisions can be based.

\section{Next steps for the cellars}

During the implementation phase of the ideal framework, cellars can determine whether the measurement framework is practical and relevant and provide feedback as to required adaption. In order to ensure future benchmarking capability, a bi-annual session between cellars is proposed to facilitate collaborative updating of the framework. After the framework has been implemented and the first measurement and internal benchmarking exercise have been completed, the first improvement cycle can be initiated, namely the plando-check-act cycle. This is an iterative process cycle that can help improve the measuring and internal benchmarking results of a cellar. This enables them to track their performance 
over a period of time and react to that while measuring their progress. After a sufficient number of cellars have performed internal benchmarking, cellars can in future perform external benchmarking to track their performance against the industry's performance. This will ultimately enable benchmarking against competing supply chains, both within South Africa and abroad, such as in Australia, Argentina and Chile.

\section{Practical implications}

The outcome of this study was well received by interviewed participants and industry bodies. Many of the metrics have already been implemented at some of the cellars involved in the study and the first steps have been taken towards a benchmarking platform with continuous measurements being taken centrally, that is, developing a technology platform to continuously measure the quantitative metrics of the Iteration 3 framework.

\section{Limitations of the study}

The lack of information available in the wine industry could initially limit the implementability of the measurement framework. The supply chain maturity of the wine industry needs some attention from industry bodies that could provide training and systems to fast-track this learning curve.

The framework proposed in this article measures only the performance of the direct supply chain. There is therefore a risk of sub-optimisation within the supply chain; however, the measurement culture needs to be initiated at firm-level. Once the measurement framework for the direct supply chain is embedded, this needs to be expanded to the extended supply chain and then the ultimate supply chain, as defined in the literature review.

Because of continued challenges with defining and measuring the SCOR agility attribute, metrics for this attribute are not included in the ideal framework yet. A significant amount of work is being extended in developing metrics for this attribute, as it is a key performance area that will influence international competitiveness. This will be reported on in subsequent publications.

\section{Conclusion}

The key objectives of this study were met. An ideal performance measurement framework for the South African bulk export wine segment was developed, informed by the SCOR framework, industry priorities and the availability of supply chain information in the bulk export chain.

Progress in relation to supply chain maturity is mostly gradual. Initiating a measurement culture and demonstrating the benefits of both internal and external benchmarking will aid this process. However, in order to ensure adoption by industry, the metrics had to be customised in such a way that the framework, and resulting data, could be realistically completed and applied in a meaningful way, while enabling future benchmarking. In support of the last-mentioned, the objective remained to use the SCOR metrics as reference point for the ideal framework to ensure the future scaling ability of the framework; as the cellars advance to higher maturity levels, the framework, being based on the SCOR model, can be expanded accordingly.

The framework will enable cellars to measure their own performance and compare their supply chain performance to the industry average and against industry leaders, as well as ultimately against international competitors. This will highlight individual cellar's process issues and ultimately enable the South African wine industry participants to improve supply chain performance, positively impacting the profitability of the industry.

As the measurement culture in the industry matures, collaboration with other stakeholders in the supply chain to optimise all the links in the chain to the benefit of the total chain becomes a possibility (Lambert \& Pohlen 2008).

\section{Acknowledgements}

Industry partners Vinpro and Winetech supplied the necessary industry contacts and funding for the project. This research forms part of a registered 3-year Technology and Human Resources for Industry Programme (THRIP) project. THRIP is a partnership programme that is funded by the South African Department of Trade and Industry and managed by the National Research Foundation (NRF).

\section{Competing interests}

The authors declare that they have no financial or personal relationships that may have inappropriately influenced them in writing this article.

\section{Authors' contributions}

J.B.S. contributed to desktop research, workshop facilitation and writing. J.v.E. contributed to project management, stakeholder liaison, methodology design, workshop facilitation, strategic interpretation and writing. F.E.v.D. was involved in stakeholder liaison, strategic interpretation and synthesising of workshop outputs.

\section{References}

Akyuz, G., \& Erkan, T., 2010, 'Supply chain performance measurement: A literature review', International Journal of Production Research 48(17), 5137-5155. https:// doi.org/10.1080/00207540903089536

APICS SCC, 2012, PWC-SCORmark frequently asked questions, viewed 26 April 2017 from http://www.apics.org/docs/default-source/scc-non-research/scormark_faq. pdf?sfursn=2

APICS SCC, 2017, The most recognized supply chain framework, viewed 28 April 2017 from http://www.apics.org/apics-for-business/products-and-services/apics-sccframeworks/scor

Balanced Scorecard Institute, 2017, Balanced scorecard basics, viewed 12 May 2017, from http://balancedscorecard.org/Resources/About-the-Balanced-Scorecard

Beamon, B.M., 1999, 'Measuring supply chain performance', International Journal of Operations and Production Management 19(3), 275-292. https://doi.org/ 10.1108/01443579910249714

Camerinelli, E., 2009, Measuring the value of the supply chain - Linking financial performance and supply chain decisions, Ashgate Publishing Company, Burlington. 
Christopher, M., 2005, Logistics and Supply Chain Management: Creating valueadding networks, 3rd edn., Pearson Education Limited, Edinburgh Gate.

Conningarth Economists, 2015, Final Report - Macroeconomic Impact of the Wine Industry on the South African Economy (also with reference to the Impacts on the Western Cape), viewed 12 May 2017, from http://www.sawis.co. za/info/download/Macro-economic_impact_study___Final_Report_Version_4_ 30Jan2015.pdf

Creswell, J.W. \& Plano Clark, V.L., 2006, Designing and conducting mixed methods research, Sage, Thousand Oaks, CA.

Estampe, D., Lamouri, S., Paris, J.L. \& Brahim-Djelloul, S., 2010, 'A framework for analysing supply chain performance evaluation models', International Journal of Production Economics 142(2), 247-258. https://doi.org/10.1016/j.ijpe.2010. Production

Garcia, F., Marchetta, M., Camargo, M., Morel, L. \& Forradellas, R., 2011, 'A framework for measuring logistics performance in the wine industry', Master's thesis, School of Engineering, National University of Cuyo, Centro Universitario.

Gunasekaran, A., Patel, C. \& McGaughey, R.E., 2004, 'A framework for supply chain performance measurement', International Journal of Production Economics 87(3), 333-347. https://doi.org/10.1016/j.ijpe.2003.08.003

Jooste, C., Van Eeden, J. \& Van Dyk, E, 2015, 'South African Wine Supply Chain Performance Measurement Framework', in W. Kersten, T. Blecker \& C.M. Ringle (eds.), Hamburg International Conference of Logistics (HICL), Hamburg, Germany, University of Hamburg, 2015, pp. 305-332.

Kaplan, R.S. \& Norton, D.P, 2005, 'The balanced scorecard - Measures that drive performance', Harvard Business Review 83(7), 172-180.

Lambert, D.M. \& Pohlen, T., 2008, 'Chapter 15: Supply chain management performance measurement', in D.M. Lambert (ed.), Supply chain management: Processes, partnerships, performance, 3rd edn, pp. 283-302, Supply Chain Management Institute, Sarasota, FL.

Lockamy, A. \& McCormack, K., 2004, 'The development of a supply chain management process maturity model using the concepts of business process orientation' Supply Chain Management: An International Journal 9(4), 272-278. https://doi. org/10.1108/13598540410550019
Mentzer, J.T., DeWitt, W., Keebler, J.S., Min, S., Nix, N.W., Smith, C.D. \& Zacharia, Z.G., 2001, 'Defining supply chain management', Journal of Business Logistics 22(2), 1-25. https://doi.org/10.1002/j.2158-1592.2001.tb00001.x

Neely, A., 2002, Business performance measurement - Theory and Practice, Cambridge University Press, Cambridge.

Pero, M., Rossi, T., Noe, C. \& Sianesi, A., 2010, 'An exploratory study of the relation between supply chain topological features and supply chain performance', International Journal of Production Economics 123(2), 266-278. https://doi org/10.1016/j.ijpe.2009.08.030

PwC, 2014, Are you competing? The South African wine industry: Insights survey 2014 viewed 10 May 2017, from https://www.pwc.co.za/en/assets/pdf/wine-insightssurvey-2014.pdf

SAWIS, 2017, Harvest Reports 2012, 2013, and 2014, viewed 10 May 2017, from http://www.sawis.co.za/info/news.php

SurveyMonkey, 2015, Palo Alto, California, USA, viewed 15 February 2015, from http://www.surveymonkey.com

Transnet, 2014, Transnet national ports authority port development framework plans 2014, viewed 10 May 2017, from http://www.transnetnationalportsauthority. net/Infrastructure $\% 20$ and $\% 2$ Port $\% 20$ Planning/Documents/Port $\% 20$ Plans $\% 20$ 2014\%20(Final\%20Versions\%20for $\% 20$ Site).pdf

Van Eeden, J., Louw, J., Goedhals-Gerber, L., \& Van Dyk, F., 2013, Wine supply chain survey 2012: Findings and challenges, viewed 12 May 2017, from http://www. embassyconferences.co.za/media/file_icons/Wine $\% 20$ Supply $\% 20$ Chain $\% 20$ Survey.pdf

Van Eeden, J., Louw, J.J., Van Dyk, F.E., Jooste, C., Roos, T. \& Smit, J.B., 2014, 'Development of supply chain performance measurement framework for the South African Wine Industry', in S. Cholette \& A. Mac Cawley (eds.), Third International Workshop on Food Supply Chains, San Francisco, USA, San Francisco State College of Business 2015(2.5), 1-12.

Vitasek, K. \& Symmes, S., 2007, The Perfect Order - A customer-focused measure, viewed 08 May 2017, from http://www.supplychainbrain.com/news/e03.21.07. newsletter.htm

WOSA, 2015, The industry statistics: Total SA exports, viewed 12 May 2017, from http://www.wosa.co.za/The-Industry/Statistics/SA-Wine-Industry-Statistics/ 


\section{Appendix 1}

TABLE 1-A1: Formulas to calculate metrics in the ideal framework.

\begin{tabular}{|c|c|}
\hline Number & Formula (As referred to in Table 3) \\
\hline 1 & Delivery performance to customer commit date $=\frac{\text { number of orders received on time by customer }}{\text { total number of orders }} \times 100$ \\
\hline 2 & Documentation accuracy $=\frac{\text { number of orders with perfect documentation }}{\text { total number of orders }} \times 100$ \\
\hline 3 & $\%$ Orders in perfect condition $=\frac{\text { number of orders received in perfect condition }}{\text { total number of orders }} \times 100$ \\
\hline 4 & Order fulfilment cycle time $=$ Cycle time $($ Order to port $)+$ Cycle time $($ port to on ship $)+$ Cycle time $($ on ship to POD $)$ \\
\hline $5 \dagger$ & Transportation cost $=$ cost of transporting the bulk wine that is being exported to customers \\
\hline 6 & Purchased material cost $=$ cost of chemicals, cleaning and filtration \\
\hline 7 & Production labour cost $=$ cost to company of personnel responsible for making the wine \\
\hline 8 & Return cost $=$ cost of product returns due to quality or other problems \\
\hline 9 & Storage cost $=\sum($ All cost associated with tanks that store bulk wine to be exported $)$ \\
\hline 10 & IDOS bulk export $=\frac{\text { average litres of export bulk wine in inventory for quarter }}{(\text { litres of export bulk wine sold for quarter }) \div 90}$ \\
\hline 11 & IDOS contracted bulk $=\frac{\text { average litres of contracted bulk wine in inventory for quarter }}{(\text { litres of contracted bulk wine sold for quarter }) \div 90}$ \\
\hline 12 & IDOS spot bulk $=\frac{\text { average litres of spot bulk wine in inventory for quarter }}{(\text { litres of spot bulk wine sold for quarter }) \div 90}$ \\
\hline 13 & Creditor days $=\frac{\text { gross accounts payable for dry goods }}{\text { gross dry goods purchased } \div 365}$ \\
\hline 14 & Debtor days $=\frac{\text { gross accounts receivable for packaged local wine }}{\text { gross sales of packaged local wine } \div 365}$ \\
\hline 15 & Cash-to-cash cycle time $=$ IDOS + days sales outstanding - days payable outstanding \\
\hline
\end{tabular}

$\dagger$, Equations 5-9 have been simplified in this table, but require further assistance in identifying the appropriate protocol for implementation. 